\title{
Comparative Study of Textural Characteristics on Methane Adsorption for Carbon Spheres Produced by $\mathrm{CO}_{2}$ Activation
}

\author{
Wen Yang, Yanyan Feng, and Wei Chu \\ Department of Chemical Engineering, Sichuan University, Chengdu 610065, China \\ Correspondence should be addressed to Wei Chu; chu1965chengdu@163.com
}

Received 13 February 2014; Revised 3 June 2014; Accepted 3 June 2014; Published 17 June 2014

Academic Editor: Dmitry Murzin

Copyright (C) 2014 Wen Yang et al. This is an open access article distributed under the Creative Commons Attribution License, which permits unrestricted use, distribution, and reproduction in any medium, provided the original work is properly cited.

\begin{abstract}
Resorcinol-formaldehyde resin polymer was used as raw material for preparation of carbon spheres. Samples were treated with $\mathrm{CO}_{2}$ flow at $850^{\circ} \mathrm{C}$ by varying activation times. The $\mathrm{CO}_{2}$ activation granted better pore development of pore structure. The experimental data of $\mathrm{CH}_{4}$ adsorption as a function of equilibrium pressure was fitted by Langmuir and Dubinin-Astakhov (D-A) models. It was concluded that the high surface area and micropore volume of carbon spheres did unequivocally determine methane capacities. In addition, a thermodynamic study of the heat of adsorption of $\mathrm{CH}_{4}$ on the carbon spheres was carried out. Adsorption of $\mathrm{CH}_{4}$ on carbon spheres showed a decrease in the adsorption heat with $\mathrm{CH}_{4}$ occupancy, and the heat of adsorption fell from 20.51 to $12.50 \mathrm{~kJ} / \mathrm{mol}$ at $298 \mathrm{~K}$ and then increased to a little higher values at a very high loading (>0.70), indicating that $\mathrm{CH}_{4} / \mathrm{CH}_{4}$ interactions within the adsorption layer became significant.
\end{abstract}

\section{Introduction}

Energy sources as an alternative to conventional fuels are required for a sustainable energy supply and progressively more strict environmental rules $[1,2]$. With this background, coalbed methane (CBM) [2-6], mainly $\mathrm{CH}_{4}$ with the low level of $\mathrm{CO}_{2}$ and other hydrocarbon gases, is becoming an increasingly important energy resource; that is, $\mathrm{CH}_{4}$ can be considered as a new energy resource $[3,7]$.

However, as one of the most important greenhouse gases, the efficient storage of $\mathrm{CH}_{4}$ is necessary [8-12]. Up to now, many studies have been carried out on the storage of large amounts of $\mathrm{CH}_{4}$ [12]. Compared with liquefaction and compression for storing $\mathrm{CH}_{4}$, adsorption in porous materials has the advantage at relatively low pressure and ambient temperature and is vital to numerous engineering processes and industrial applications [8]. Carbonaceous materials are particularly attractive as the adsorbent because they are lightweight, abundantly available, and simple to produce and can effectively increase the amounts of stored gases [13-17]. The fabrication and tuning of carbonaceous materials such as activated carbons (ACs) and carbon nanotubes [18-20] are important research areas with respect to achieving storage of high amounts of $\mathrm{CH}_{4}$ [21-25].

$\mathrm{AC}$ is one of the most excellent carbonaceous materials widely developed for various industries $[9,10,26-32]$. As a sort of well-developed porous solid, the nature of the microstructure of AC has been reported to have an effect on their adsorptive capacities for $\mathrm{CH}_{4}[1,33-35]$. In addition, the pore structure offers the potential to adjust the thermodynamic properties of adsorption. Herein, an effective approach for investigating the methane adsorption capacity and tuning the thermodynamics of adsorption is by controlling the pore structure $[2,10,36,37]$. However, the pore structure of ACs is highly dependent on the activation process, among which thermal or physical activation of ACs has been widely used. One-step activation with $\mathrm{CO}_{2}$ has been used to prepare ACs at laboratory scale and carbon atoms are extracted from the structure of the porous carbon according to the following endothermic reactions:

$$
\mathrm{C}+\mathrm{CO}_{2} \longrightarrow 2 \mathrm{CO}
$$

resulting in the well-developed microporosities of the prepared ACs [36]. 
Hence, in the present study, we investigated the effect of the textural characteristics of carbon spheres on their $\mathrm{CH}_{4}$ adsorption capacities. Sample, with resorcinol-formaldehyde resin polymer used as the raw material, was treated with $\mathrm{CO}_{2}$ flow at $850^{\circ} \mathrm{C}$ by varying activation time to achieve different pore structures. The texture was determined by $\mathrm{N}_{2}$ adsorption/desorption at $77 \mathrm{~K}$, scanning electron microscopy (SEM), and Raman spectroscopy. Detailed analyses of the texture allowed the investigation of pore structures in which the adsorption behaviors took place. The data of $\mathrm{CH}_{4}$ adsorption equilibrium were measured by a volumetric method at pressures up to $\sim 5 \mathrm{MPa}$ and temperature $298 \mathrm{~K}$ which was relevant to gas storage under geological conditions and continually fitted to the Langmuir and Dubinin-Astakhov (D-A) equations, respectively. Furthermore, the results of $\mathrm{CH}_{4}$ adsorption were discussed with regard to the textural characteristics, such as the pore structure and degree of graphitization. In addition, a thermodynamic study of the heat of adsorption of $\mathrm{CH}_{4}$ on the carbon spheres was also carried out.

\section{Experimental}

2.1. Sample Preparation. The RF resins spheres were typically synthesized by using resorcinol and formaldehyde solution as precursors, similarly described in the previous literature [38]. At first, $6 \mathrm{~mL}$ of the ammonia aqueous solution $\left(\mathrm{NH}_{4} \mathrm{OH}\right.$, $25 \mathrm{wt} \%)$ was mixed with a solution containing absolute ethanol (EtOH, $480 \mathrm{~mL})$ and deionized water $(1200 \mathrm{~mL})$ and stirred for more than $1 \mathrm{~h}$. Subsequently, resorcinol $(12 \mathrm{~g})$ was added, followed by adding $16.8 \mathrm{~mL}$ of the formaldehyde solution and continually stirring for $24 \mathrm{~h}$ with the speed of $300 \mathrm{r} / \mathrm{min}$ at $30^{\circ} \mathrm{C}$, and then kept at $100^{\circ} \mathrm{C}$ for $24 \mathrm{~h}$ in a Teflon-lined autoclave. The solid product was obtained by centrifugation and air-dried at $100^{\circ} \mathrm{C}$ for $24 \mathrm{~h}$. Lastly, the RF resin spheres were heated to $700^{\circ} \mathrm{C}$ under Ar atmosphere with a heating rate of $2^{\circ} \mathrm{C} / \mathrm{min}$ and then maintained at $700^{\circ} \mathrm{C}$ for $2 \mathrm{~h}$ (named as CSO) for carbonization.

After carbonization, the resulting products were taken out and used for $\mathrm{CO}_{2}$ activation. The products were heated up to $850^{\circ} \mathrm{C}$ with a heating rate of $2^{\circ} \mathrm{C} / \mathrm{min}$, and $\mathrm{CO}_{2}$ stream with a flow rate of $100 \mathrm{~mL} / \mathrm{min}$ was used for 3 9 h to obtain carbon spheres with different pore structures (denoted by CS3, CS6, and CS9, resp.) [36].

2.2. Characterization. The textural characterization of the four samples was obtained by $\mathrm{N}_{2}$ adsorption/desorption isotherms, determined at $77 \mathrm{~K}$ with a NOVA1000e surface area and pore size analyzer (Quantachrome Company). The specific surface areas were determined according to the BET method. Total pore volume was directly calculated from the volume of nitrogen held at $p / p_{0}=0.98 \sim 0.99$; the volume of micropore and pore size distributions (PSDs) were estimated using the D-A equation $[2,3]$.

Surface morphology was investigated by scanning electron microscopy (SEM) (Hitachi S-4800, Japan) [39].

The Raman spectroscopy of the samples was measured with a Raman microspectrometer (Renishaw SystemInVia)

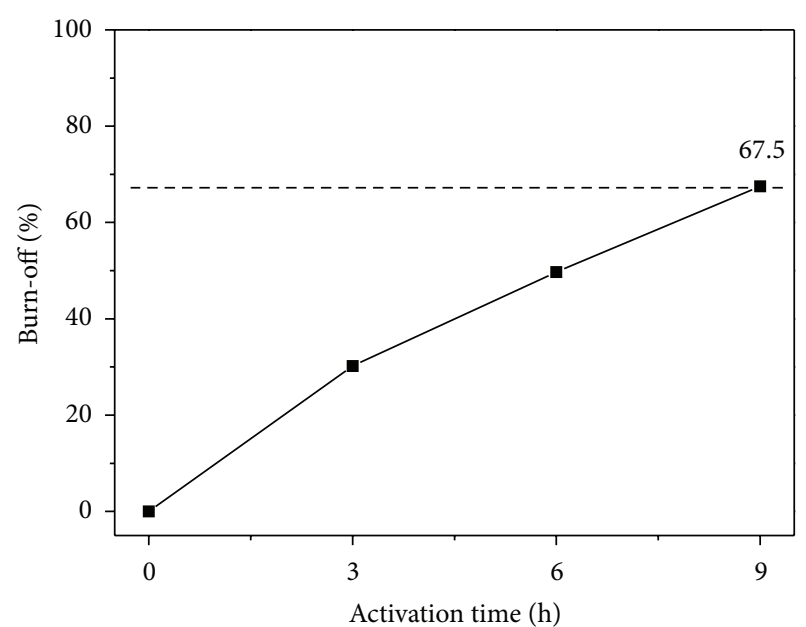

FIGURE 1: Evolution of burn-off versus activation time for carbon spheres treated in $\mathrm{CO}_{2}$.

using an argon laser as the excitation $(\lambda=514.5 \mathrm{~nm})$. The spectra were recorded in the wave number range of $400 \sim$ $4000 \mathrm{~cm}^{-1}[40,41]$, and the intensities of $\mathrm{D}$ and $\mathrm{G}$ bands were measured using a Lorentzian curve-fitting procedure [25, 42].

2.3. Methane Adsorption. Methane adsorption measurements were conducted using a volumetric method similar to that previously described [2-4]. The experimental devices were placed in a temperature-controlled oven to ensure the constant temperature throughout the adsorption process. The purities of helium and methane were 99.999\% and $99.99 \%$, respectively. Before the measurement, the sample was degassed for about $3 \mathrm{~h}$. After degassing, helium expansion was performed for the calibration of the void volume in the adsorption setup. Subsequently, methane adsorption was measured at $298 \mathrm{~K}$ under the pressure range 0 5.0 MPa.

\section{Results and Discussion}

3.1. Textural and Structural Characteristics. The weight loss (burn-off) as a function of residence time of activated carbon spheres was plotted in Figure 1. With the activation time increasing, the burn-off became much higher. As the burnoff increased, the elementary crystallites and defects became exposed to the activating agent $\mathrm{CO}_{2}$ for further development of porosity [43-45].

The $\mathrm{N}_{2}$ adsorption-desorption isotherms, pore size distribution (PSD), and textural characteristics of the pristine sample and the corresponding $\mathrm{CO}_{2}$ activated samples were presented in Figures 2 and 3 and Table 1, respectively. As shown in Figure 2, the samples of CS3, CS6, and CS9 presented largely similar adsorption-desorption isotherms between types I and IV, indicating that not only micropores but also mesopores were developed in these porous samples. For the activated carbon spheres, the increase in the activation time provoked a progressive increase in $\mathrm{N}_{2}$ adsorption capacity. For the maximum activation time of $9 \mathrm{~h}$, a BET surface area of $1145.0 \mathrm{~m}^{2} / \mathrm{g}$ and a D-A micropore volume of 
TABLE 1: Structural characteristics of the studied samples.

\begin{tabular}{lccccc}
\hline Sample & $\begin{array}{c}\text { Specific surface } \\
\text { area }\left(\mathrm{BET}, \mathrm{m}^{2} / \mathrm{g}\right)\end{array}$ & $\begin{array}{c}\text { Micropore } \\
\text { volume } \\
\left(\mathrm{D}-\mathrm{A}, \mathrm{cm}^{3} / \mathrm{g}\right)\end{array}$ & $\begin{array}{c}\text { Total pore } \\
\text { volume }\left(\mathrm{cm}^{3} / \mathrm{g}\right)\end{array}$ & $V_{\text {micro }} / V_{\text {total }}(\%)$ & $\begin{array}{c}\text { Average pore } \\
\text { diameter }(\mathrm{nm})\end{array}$ \\
\hline CS0 & 422.7 & 0.219 & 0.238 & 92.02 & 2.254 \\
CS3 & 658.4 & 0.336 & 0.428 & 78.50 & 2.602 \\
CS6 & 881.7 & 0.461 & 0.557 & 82.76 & 2.529 \\
CS9 & 1145.0 & 0.639 & 0.732 & 87.30 & 2.556 \\
\hline
\end{tabular}

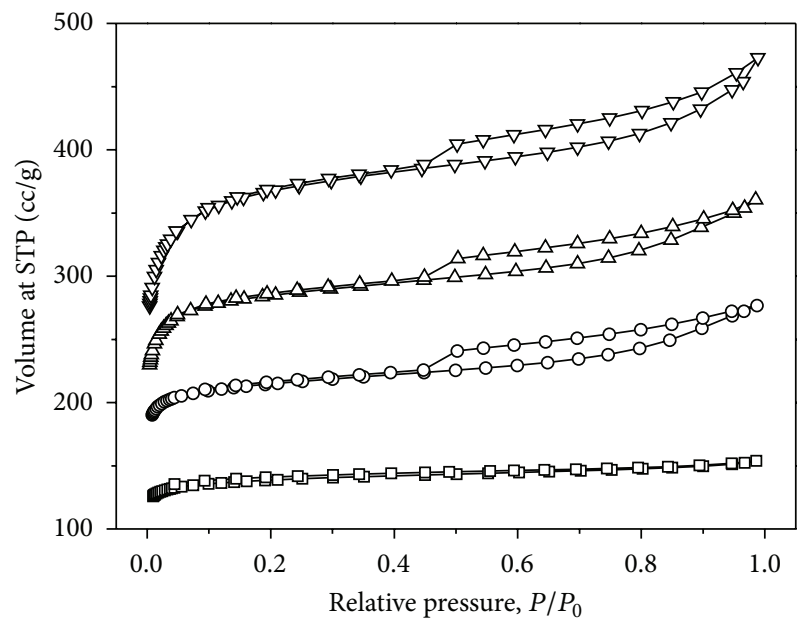

FIGURE 2: $\mathrm{N}_{2}$ adsorption-desorption isotherms (77 K) corresponding to the four samples. $\square$ : CS0; O: CS3; $\triangle$ : CS6; and $\nabla$ : CS9.

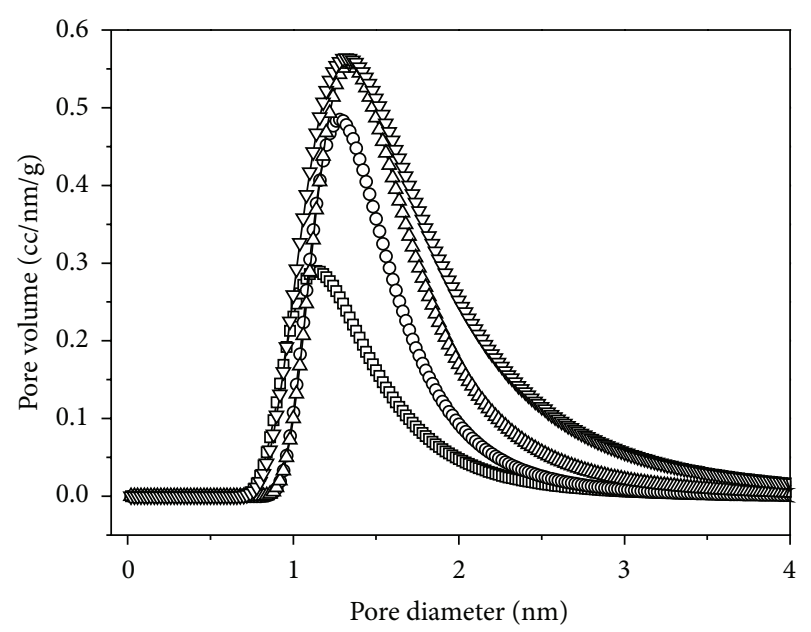

FIgure 3: Pore size distributions obtained applying the D-A equation to the $\mathrm{N}_{2}$ adsorption-desorption data. $\square$ : CS0; O: CS3; $\triangle$ : CS6; and $\nabla:$ CS9.

$0.639 \mathrm{~cm}^{3} / \mathrm{g}$ were reached. It was clear to see that the prepared samples had similar PSDs determined from the isotherms with similar shapes.

The specific surface area and micropore volume of the prepared carbon spheres were summarized in Table 1. The fraction of microporosity depended heavily on the degree of activation to which the pristine carbon spheres were subjected. We observed that this parameter has an important role in determining the textural characteristics of the porous samples. It could be seen that the pore structure of the prepared samples strongly relied on the activation time. As displayed in Table 1, the carbon spheres activated at $9 \mathrm{~h}$ possessed higher surface area, larger than $1100 \mathrm{~m}^{2} / \mathrm{g}$, while the samples activated at shorter times had a much lower surface area, especially for the pristine sample CSO. Maximum surface area was obtained for the sample of CS9 $\left(1145.0 \mathrm{~m}^{2} / \mathrm{g}\right)$, which may be because most of $\mathrm{CO}_{2}$ could efficiently diffuse onto and act with the carbons on the particle surface of the samples during the activation process, resulting in the well-developed microporosity. Moreover, the longer the sample is activated, the more the burn-off is, thus affecting the pore structure of the treated sample and leading to the higher pore volume.

More interestingly, the porosity of these carbon spheres was made up of pores in the micropore-mesopore range (sizes between $0.8 \mathrm{~nm}$ and $3 \mathrm{~nm}$ ) as evidenced by the PSDs shown in Figure 3. At high activation times, a development of some micropores and the widening of PSDs continued, resulting in the development of wider micropores and a right shift of the maximum peak to mesopores. In summary, the $\mathrm{CO}_{2}$ activation process carried out promoted the $\mathrm{N}_{2}$ adsorption capacity (Figure 2) together with a modest widening of the PSDs (Figure 3).

To further investigate the effect of activation time on the porous carbon spheres, SEM observation was employed to obtain the morphology of the resulting samples. As shown in Figure 4, the pristine carbon spheres exhibited a spherelike morphology, and the primary particle size was about $400 \sim 500 \mathrm{~nm}$. It could be seen that, in spite of the activation time, the samples of CS3, CS6, and CS9 presented no apparent differences in morphology. Comparatively, the CS9 carbon displayed a much rougher surface with more defects on the particle surface due to the accelerated activation process at high activation time, suggesting that a drastic surface morphological change has occurred during the activation process.

The Raman spectra of the four samples, shown in Figure 5, presented a prominent G-band (graphite) at $1580 \mathrm{~cm}^{-1}$ and a less-intense D-band (defects) at $1350 \mathrm{~cm}^{-1}$ in the firstorder region. The second-order Raman spectrum showed the $\mathrm{G}^{\prime}$ band which is characteristic of tridimensional ordered materials. The D-band and G-band strengths were suggested to be proportional to the likely of a 6 -fold aromatic ring 


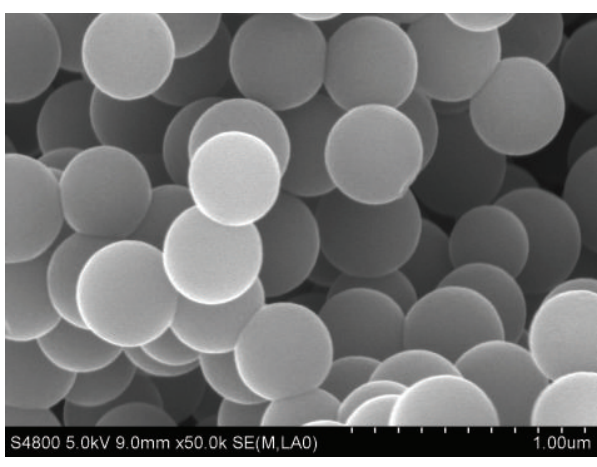

(a)

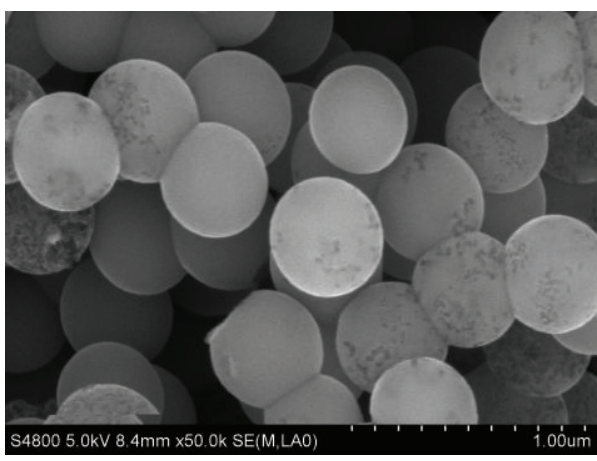

(c)

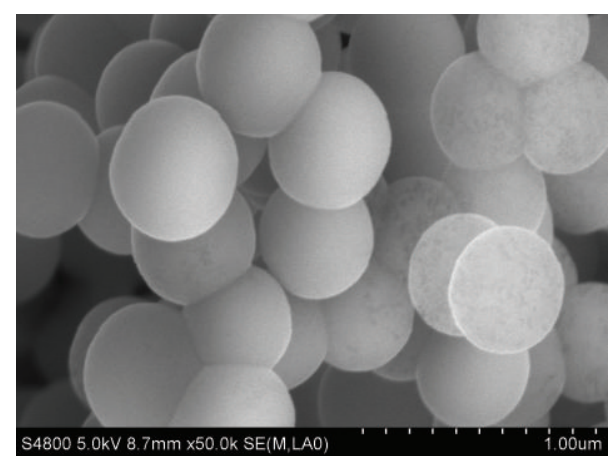

(b)

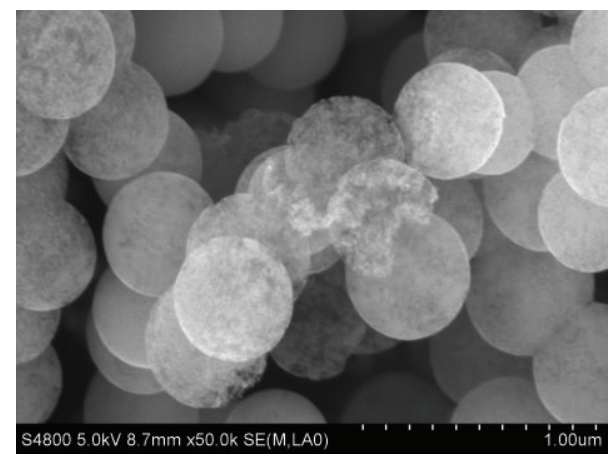

(d)

FIgURE 4: SEM images of the prepared samples. (a) CS0, (b) CS3, (c) CS6, and (d) CS9.

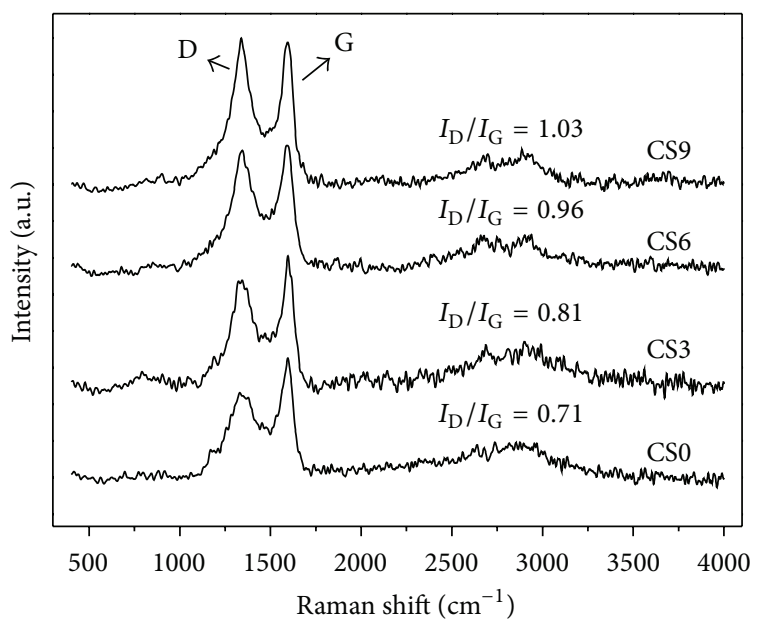

FIGURE 5: Raman spectra for the samples prepared by $\mathrm{CO}_{2}$ activation.

in the sample [6], and $I_{\mathrm{D}} / I_{\mathrm{G}}$ was chosen to represent the evolution of the microstructure of the carbon spheres during the activation process. Figure 5 showed almost a linear correlation between activation time and defects. When subjected to high activation time, it was enough for the growth of disordered structure and was tending to a worse orientation of the sample. With the increase of activation time, the D-band intensity of the samples went higher, and the intensity of G-band changed little. The D-band presented more intensely, suggesting more defects, and an increasing amount of disordered structure of the sample occurred. As a result, compared with the pristine carbon spheres without activation treatment, the $\mathrm{CO}_{2}$ activated samples became more disordered. The increase in the specific surface area, PSDs, the average pore diameter, and the results of SEM also reflected the structure disordering with an increasing activation time.

3.2. Methane Adsorption Performance. The methane adsorption isotherms of the carbon spheres at $298 \mathrm{~K}$ and pressures up to 5.0 MPa were presented in Figures 6 and 7, respectively. The methane adsorption isotherms were Type I of IUPAC, and the capacity of methane adsorbed increased with the increase in activation time. The adsorption isotherms were then analyzed by two models, that is, Langmuir (dotted lines in Figure 6) and D-A models (dotted lines in Figure 7). It can be seen that both models fitted the data well, and the adsorption parameters of the two models were given in Table 2.

The parameters obtained from Langmuir model have been widely used in evaluating the methane adsorption capacities. $n_{0}$ represents the Langmuir maximum adsorption capacity and Langmuir constant $b$ is the reciprocal of the pressure when the adsorption capacity reaches $50 \%$ of the maximum adsorption capacity. The parameter $t$ in D-A model describes the surface heterogeneity. It has been reported that the surface of the adsorbent is less heterogeneous when the $t$ value is approaching 3 more $(t<3)$. The parameter $E$ in $\mathrm{D}$-A model is the characteristic energy describing the 
TABLE 2: Adsorption parameters of the Langmuir model and D-A model of methane adsorption at $298 \mathrm{~K}$.

\begin{tabular}{|c|c|c|c|c|c|}
\hline \multirow{2}{*}{ Sample } & \multicolumn{2}{|c|}{ Langmuir model } & \multicolumn{3}{|c|}{ D-A model } \\
\hline & $n_{0}(\mathrm{mg} / \mathrm{g})$ & $b\left(\mathrm{MPa}^{-1}\right)$ & $W_{0}(\mathrm{mg} / \mathrm{g})$ & $E(\mathrm{KJ} / \mathrm{mol})$ & $t$ \\
\hline CSO & 49.31 & 0.775 & 44.87 & 7.112 & 1.714 \\
\hline $\mathrm{CS} 3$ & 70.78 & 0.653 & 64.41 & 6.648 & 1.598 \\
\hline CS6 & 102.47 & 0.447 & 81.71 & 6.205 & 1.724 \\
\hline CS9 & 115.55 & 0.611 & 90.27 & 6.898 & 2.325 \\
\hline
\end{tabular}

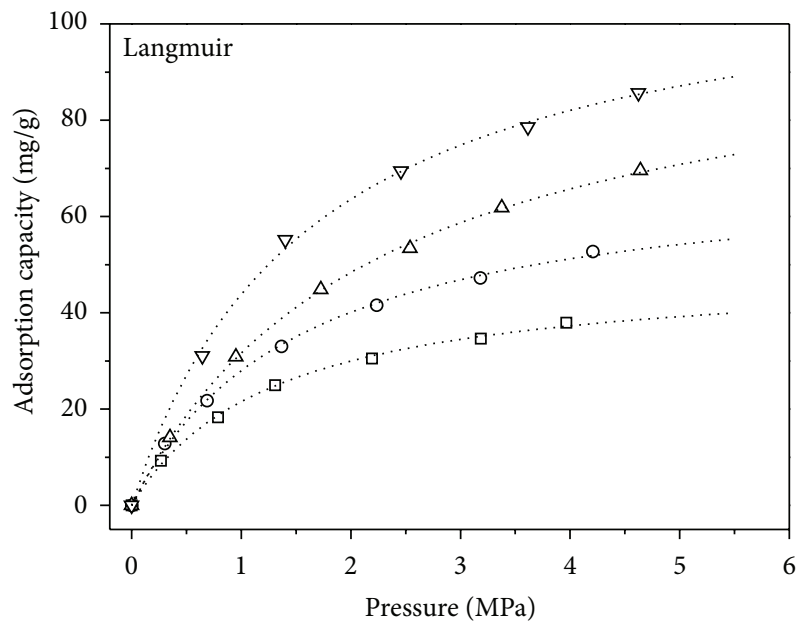

FIGURE 6: Equilibrium isotherms of methane adsorption on carbon spheres at $298 \mathrm{~K}$. $\square$ : CS0; O: CS3; $\triangle$ : CS6; $\nabla$ : CS9; and dotted line: Langmuir model.

strength of interaction between adsorbate and adsorbent $[2,4]$. Comparing with the D-A model, Langmuir model displayed a higher value of maximum adsorption capacity for the samples.

It is well known that the methane adsorption is a physical adsorption, which is mainly dependent on the micropore volume and surface area. The greatest adsorption capacity ( $115.55 \mathrm{mg} / \mathrm{g}$, Langmuir model) was obtained for the CS9 sample due to its higher surface area and abundant micropores. The carbon spheres of CS3 and CS6 exhibited much higher adsorption capacity (70.78 and $102.47 \mathrm{mg} / \mathrm{g}$, resp., Langmuir model) than the pristine sample which exhibited the smallest adsorption capacity $(49.31 \mathrm{mg} / \mathrm{g}$, Langmuir model) among all the prepared carbon spheres.

To determine the strength of the interaction between methane and the prepared samples, the heat of adsorption, $H_{\text {ads }}$, was evaluated based on the Clausius-Clapeyron equation using the methane adsorption isotherms, and these were plotted in Figure 8 against the surface loading $W / W_{0}$. Invoking the D-A model in Clausius-Clapeyron equation, an explicit expression for $H_{\text {ads }}$ can be written as below [37] for $T>T_{\text {cri }}:$

$$
H_{\mathrm{ads}}=2 \mathrm{RT}+E\left[\left(\ln \frac{W_{0}}{\mathrm{C} v_{\mathrm{a}}}\right)^{1 / t}+\frac{\alpha T}{t}\left(\ln \frac{W_{0}}{\mathrm{C} v_{\mathrm{a}}}\right)^{1-t / t}\right] .
$$

As shown in Figure 8, the $H_{\text {ads }}$ varied largely with the surface loading $W / W_{0}$ for all the samples. Before the $W / W_{0}$

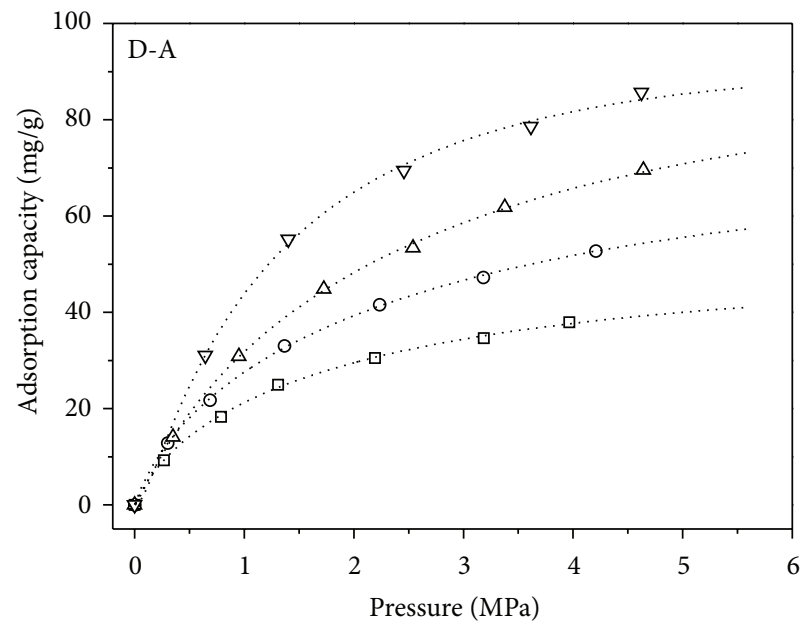

FIGURE 7: Equilibrium isotherms of methane adsorption on carbon spheres at $298 \mathrm{~K}$. $\square$ : CS0; O: CS3; $\triangle$ : CS6; $\nabla$ : CS9; and dotted line: D-A model.

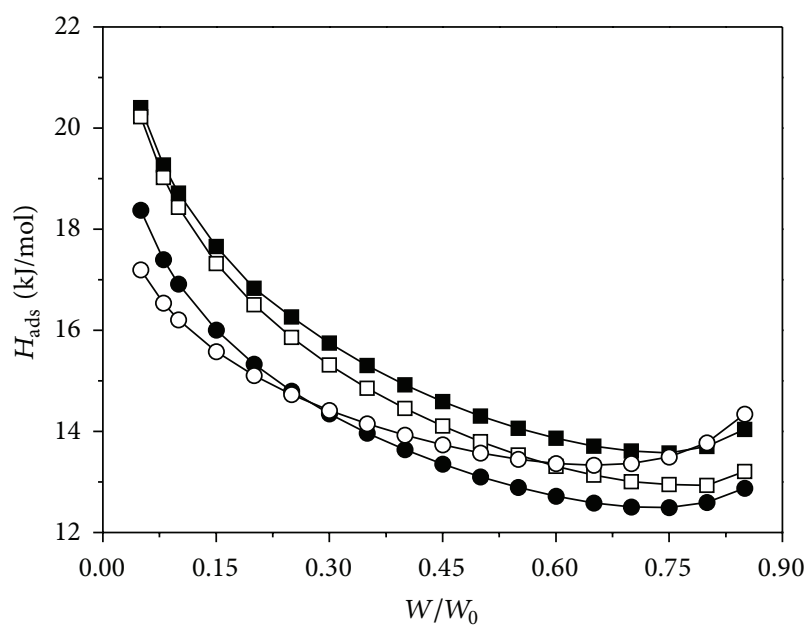

FIGURE 8: Heat of adsorption $\left(H_{\mathrm{ads}}\right)$ for methane/carbon spheres pair against different surface loading $\left(W / W_{0}\right)$ at $298 \mathrm{~K}$. $\mathbf{0}$ : CS0; $\square$ : CS3; : CS6; and O: CS9.

approached about 0.70 , the value of the $H_{\text {ads }}$ over the carbon spheres all decreased with the increase in the $W / W_{0}$. This variation of the $H_{\text {ads }}$ with the surface loading was due to the surface heterogeneity of the carbon spheres and the stronger interaction between carbon materials and methane. However, the plots of the CS0, CS6, and CS9 then increased to a little 
higher value at very high loading $(>0.70)$, indicating that the interaction between the carbon spheres and methane was weaker and methane/methane interactions within the adsorption layer became obvious. For methane adsorption, the average heat of adsorption is typically $12 \sim 20 \mathrm{~kJ} / \mathrm{mol}$, consistent with the result of our study that the $H_{\text {ads }}$ fell from 20.51 to $12.50 \mathrm{~kJ} / \mathrm{mol}$ with methane occupancy at $298 \mathrm{~K}$. It could be further seen that the $H_{\text {ads }}$ of the prepared carbon spheres dropped with the increase in activation time, which may be due to the decrease in interaction between methane and carbon materials. The high $H_{\text {ads }}$ value indicated that the prepared sample strongly interacted with methane molecules $[2,37]$.

\section{Conclusion}

In this paper, the textural characteristics of the carbon spheres were related to their methane adsorption capacities. Resorcinol-formaldehyde resin polymer was used as the raw material for the preparation of carbon spheres. Samples were treated with $\mathrm{CO}_{2}$ flow at $850^{\circ} \mathrm{C}$ by varying activation times to achieve carbon spheres of different pore structures. The $\mathrm{CO}_{2}$ activation process, granting better development of pore structure, provoked a continuous increase in the $\mathrm{N}_{2}$ adsorption capacity together with a modest widening of the PSDs. Comparatively, the CS9 displayed a much rougher surface with more defects on the particle surface due to the accelerated carbonization process at high activation time. It was long enough for the growth of disordered structure of the samples when subjected to high activation time.

The adsorption characteristics of methane onto carbon spheres were performed at $298 \mathrm{~K}$ and pressures up to 5.0 MPa by a volumetric method. The experimental data of methane adsorption as a function of equilibrium pressure was determined by fitting isotherms to Langmuir and D-A models. The methane adsorption over the carbon spheres was involved in their physical structures. It was concluded that the high surface area and micropore volume of carbon spheres did unequivocally determine methane capacities. In addition, a thermodynamic study of the heat of adsorption of methane on the carbon spheres was carried out. Adsorption of methane on carbon spheres showed a decrease in the heat of adsorption with the increase in surface loading $W / W_{0}$, and the heat of adsorption fell from 20.51 to $12.50 \mathrm{~kJ} / \mathrm{mol}$ at $298 \mathrm{~K}$ and then increased to a little higher values at very high loading $(>0.70)$, indicating that methane/methane interactions within the adsorption layer became obvious.

\section{Conflict of Interests}

The authors declare that there is no conflict of interests regarding the publication of this paper.

\section{Acknowledgment}

This work was supported by the National Basic Research Program of China (973 Program, no. 2011CB201202).

\section{References}

[1] T. A. Makal, J.-R. Li, W. Lu, and H.-C. Zhou, "Methane storage in advanced porous materials," Chemical Society Reviews, vol. 41, no. 23, pp. 7761-7779, 2012.

[2] J. Luo, Y. Liu, C. Jiang, W. Chu, W. Jie, and H. Xie, "Experimental and modeling study of methane adsorption on activated carbon derived from anthracite," Journal of Chemical and Engineering Data, vol. 56, no. 12, pp. 4919-4926, 2011.

[3] Y. Feng, W. Yang, D. Liu, and W. Chu, "Surface modification of bituminous coal and its effects on methane adsorption," Chinese Journal of Chemistry, vol. 31, no. 8, pp. 1102-1108, 2013.

[4] S. Hao, J. Wen, X. Yu, and W. Chu, "Effect of the surface oxygen groups on methane adsorption on coals," Applied Surface Science, vol. 264, pp. 433-442, 2013.

[5] A. Busch and Y. Gensterblum, "CBM and $\mathrm{CO}_{2}$-ECBM related sorption processes in coal: a review," International Journal of Coal Geology, vol. 87, no. 2, pp. 49-71, 2011.

[6] Y. Feng, C. Jiang, D. Liu, and W. Chu, "Experimental investigations on microstructure and adsorption property of heattreated coal chars," Journal of Analytical and Applied Pyrolysis, vol. 104, pp. 559-566, 2013.

[7] B. Buczek, "Nanostructural materials for energy storage systems," International Journal of Photoenergy, vol. 2011, Article ID 340540, 4 pages, 2011.

[8] Z. Chang, D.-S. Zhang, Q. Chen, and X.-H. Bu, "Microporous organic polymers for gas storage and separation applications," Physical Chemistry Chemical Physics, vol. 15, no. 15, pp. 54305442, 2013.

[9] J. R. Morris, C. I. Contescu, M. F. Chisholm et al., "Modern approaches to studying gas adsorption in nanoporous carbons," Journal of Materials Chemistry A, vol. 1, no. 33, pp. 9341-9350, 2013.

[10] Y. Xia, Z. Yang, and Y. Zhu, "Porous carbon-based materials for hydrogen storage: advancement and challenges," Journal of Materials Chemistry A, vol. 1, no. 33, pp. 9365-9381, 2013.

[11] G.-F. Zhao, P. Bai, H.-M. Zhu, R.-X. Yan, X.-M. Liu, and Z.F. Yan, "The modification of activated carbons and the pore structure effect on enrichment of coal-bed methane," AsiaPacific Journal of Chemical Engineering, vol. 3, no. 3, pp. 284291, 2008.

[12] C. Guan, L. S. Loo, K. Wang, and C. Yang, "Methane storage in carbon pellets prepared via a binderless method," Energy Conversion and Management, vol. 52, no. 2, pp. 1258-1262, 2011.

[13] M. Sevilla and A. B. Fuertes, "Sustainable porous carbons with a superior performance for $\mathrm{CO}_{2}$ capture," Energy \& Environmental Science, vol. 4, p. 1765, 2011.

[14] J. P. Marco-Lozar, M. Kunowsky, F. Suárez-García, J. D. Carruthers, and A. Linares-Solano, "Activated carbon monoliths for gas storage at room temperature," Energy and Environmental Science, vol. 5, no. 12, pp. 9833-9842, 2012.

[15] M. H. Abdel Rehim, N. Ismail, A. E.-R. A. A. Badawy, and G. Turky, "Hydrogen storing and electrical properties of hyperbranched polymers-based nanoporous materials," Materials Science and Engineering B: Solid-State Materials for Advanced Technology, vol. 176, no. 15, pp. 1184-1189, 2011.

[16] H. G. Schimmel, G. Nijkamp, G. J. Kearley, A. Rivera, K. P. De Jong, and F. M. Mulder, "Hydrogen adsorption in carbon nanostructures compared," Materials Science and Engineering B: Solid-State Materials for Advanced Technology, vol. 108, no. 1-2, pp. 124-129, 2004. 
[17] H. Takagi, H. Hatori, Y. Soneda, N. Yoshizawa, and Y. Yamada, "Adsorptive hydrogen storage in carbon and porous materials," Materials Science and Engineering B: Solid-State Materials for Advanced Technology, vol. 108, no. 1-2, pp. 143-147, 2004.

[18] L. Valentini, I. Armentano, L. Lozzi, S. Santucci, and J. M. Kenny, "Interaction of methane with carbon nanotube thin films: role of defects and oxygen adsorption," Materials Science and Engineering C, vol. 24, no. 4, pp. 527-533, 2004.

[19] I. A. A. C. Esteves, F. J. A. L. Cruz, E. A. Müller, S. Agnihotri, and J. P. B. Mota, "Determination of the surface area and porosity of carbon nanotube bundles from a Langmuirian analysis of suband supercritical adsorption data," Carbon, vol. 47, no. 4, pp. 948-956, 2009.

[20] M. A. Callejas, A. Ansón, A. M. Benito et al., "Enhanced hydrogen adsorption on single-wall carbon nanotubes by sample reduction," Materials Science and Engineering B: Solid-State Materials for Advanced Technology, vol. 108, no. 1-2, pp. 120-123, 2004.

[21] K. Vasanth Kumar and F. Rodríguez-Reinoso, "Effect of pore structure on the selectivity of carbon materials for the separation of $\mathrm{CO}_{2} / \mathrm{H}_{2}$ mixtures: new insights from molecular simulation," RSC Advances, vol. 2, no. 25, pp. 9671-9678, 2012.

[22] J. Zhou, W. Li, Z. Zhang, W. Xing, and S. Zhuo, "Carbon dioxide adsorption performance of $\mathrm{N}$-doped zeolite y templated carbons," RSC Advances, vol. 2, no. 1, pp. 161-167, 2012.

[23] C. X. Zhang, B. L. Xing, L. Y. Pan, and H. Guo, "Study on the preparation of high specific surface area coal-based activated carbon and its adsorption properties," in Proceedings of Information Technology and Environmental System Sciences (ITESS '08), vol. 1, pp. 309-315, 2008.

[24] J. R. Rangel-Mendez and F. S. Cannon, "Improved activated carbon by thermal treatment in methane and steam: physicochemical influences on MIB sorption capacity," Carbon, vol. 43, no. 3, pp. 467-479, 2005.

[25] L. Smędowski, M. Krzesińska, W. Kwaśny, and M. Kozanecki, "Development of ordered structures in the high-temperature (HT) cokes from binary and ternary coal blends studied by means of x-ray diffraction and Raman spectroscopy," Energy and Fuels, vol. 25, no. 7, pp. 3142-3149, 2011.

[26] D. Prahas, Y. Kartika, N. Indraswati, and S. Ismadji, "Activated carbon from jackfruit peel waste by $\mathrm{H}_{3} \mathrm{PO}_{4}$ chemical activation: pore structure and surface chemistry characterization," Chemical Engineering Journal, vol. 140, no. 1-3, pp. 32-42, 2008.

[27] A. Ahmadpour, B. A. King, and D. D. Do, "Comparison of equilibria and kinetics of high surface area activated carbon produced from different precursors and by different chemical treatments," Industrial and Engineering Chemistry Research, vol. 37, no. 4, pp. 1329-1334, 1998.

[28] A. Toprak and T. Kopac, "Surface and hydrogen sorption characteristics of various activated carbons developed from rat coal mine (Zonguldak) and anthracite," Chinese Journal of Chemical Engineering, vol. 19, no. 6, pp. 931-937, 2011.

[29] S. A. Mohammad, A. Arumugam, R. L. Robinson, and K. A. M. Gasem, "High-pressure adsorption of pure gases on coals and activated carbon: measurements and modeling," Energy and Fuels, vol. 26, no. 1, pp. 536-548, 2012.

[30] J. P. Marco-Lozar, A. Linares-Solano, and D. Cazorla-Amorós, "Effect of the porous texture and surface chemistry of activated carbons on the adsorption of a germanium complex from dilute aqueous solutions," Carbon, vol. 49, no. 10, pp. 3325-3331, 2011.
[31] J. Liu, W. Qu, S. W. Joo, and C. Zheng, "Effect of $\mathrm{SO}_{2}$ on mercury binding on carbonaceous surfaces," Chemical Engineering Journal, vol. 184, pp. 163-167, 2012.

[32] A. Martin, W. S. Loh, K. A. Rahman et al., "Adsorption isotherms of $\mathrm{CH}_{4}$ on activated carbon from Indonesian low grade coal," Journal of Chemical and Engineering Data, vol. 56, no. 3, pp. 361-367, 2011.

[33] Y. Cai, D. Liu, Z. Pan, Y. Yao, J. Li, and Y. Qiu, "Pore structure and its impact on $\mathrm{CH}_{4}$ adsorption capacity and flow capability of bituminous and subbituminous coals from Northeast China," Fuel, vol. 103, pp. 258-268, 2013.

[34] W. H. Lee, J. S. Park, J. H. Sok, and P. J. Reucroft, "Effects of pore structure and surface state on the adsorption properties of nano-porous carbon materials in low and high relative pressures," Applied Surface Science, vol. 246, no. 1-3, pp. 77-81, 2005.

[35] Y. Liu and J. Wilcox, "Effects of surface heterogeneity on the adsorption of $\mathrm{CO}_{2}$ in microporous carbons," Environmental Science and Technology, vol. 46, no. 3, pp. 1940-1947, 2012.

[36] A. Arami-Niya, W. M. A. W. Daud, and F. S. Mjalli, "Comparative study of the textural characteristics of oil palm shell activated carbon produced by chemical and physical activation for methane adsorption," Chemical Engineering Research and Design, vol. 89, no. 6, pp. 657-664, 2011

[37] K. A. Rahman, A. Chakraborty, B. B. Saha, and K. C. Ng, "On thermodynamics of methane + carbonaceous materials adsorption," International Journal of Heat and Mass Transfer, vol. 55, no. 4, pp. 565-573, 2012.

[38] J. Liu, S. Z. Qiao, H. Liu et al., "Extension of the stöber method to the preparation of monodisperse resorcinol-formaldehyde resin polymer and carbon spheres," Angewandte Chemie International Edition, vol. 50, no. 26, pp. 5947-5951, 2011.

[39] Y. Zhang, L. Chen, W. Yang et al., "Hierarchical graphite oxide fabricated from graphite via electrochemical cleavage as an anode material for lithium ion batteries," RSC Advances, vol. 3, no. 31, pp. 12758-12764, 2013.

[40] D. González, M. A. Montes-Morán, and A. B. Garcia, "Graphite materials prepared from an anthracite: a structural characterization," Energy and Fuels, vol. 17, no. 5, pp. 1324-1329, 2003.

[41] J. Zhou, J. He, C. Zhang et al., "Mesoporous carbon spheres with uniformly penetrating channels and their use as a supercapacitor electrode material," Materials Characterization, vol. 61, no. 1, pp. 31-38, 2010.

[42] D. González, M. A. Montes-Morán, and A. B. Garcia, "Influence of inherent coal mineral matter on the structural characteristics of graphite materials prepared from anthracites," Energy and Fuels, vol. 19, no. 1, pp. 263-269, 2005.

[43] F. Rodríguez-Reinoso and M. Molina-Sabio, "Activated carbons from lignocellulosic materials by chemical and/or physical activation: an overview," Carbon, vol. 30, no. 7, pp. 1111-1118, 1992.

[44] F. Rodríguez-Reinoso, M. Molina-Sabio, and M. T. González, "The use of steam and $\mathrm{CO}_{2}$ as activating agents in the preparation of activated carbons," Carbon, vol. 33, no. 1, pp. 15-23, 1995.

[45] N. P. Wickramaratne and M. Jaroniec, "Activated carbon spheres for $\mathrm{CO}_{2}$ adsorption," ACS Applied Materials and Interfaces, vol. 5, no. 5, pp. 1849-1855, 2013. 

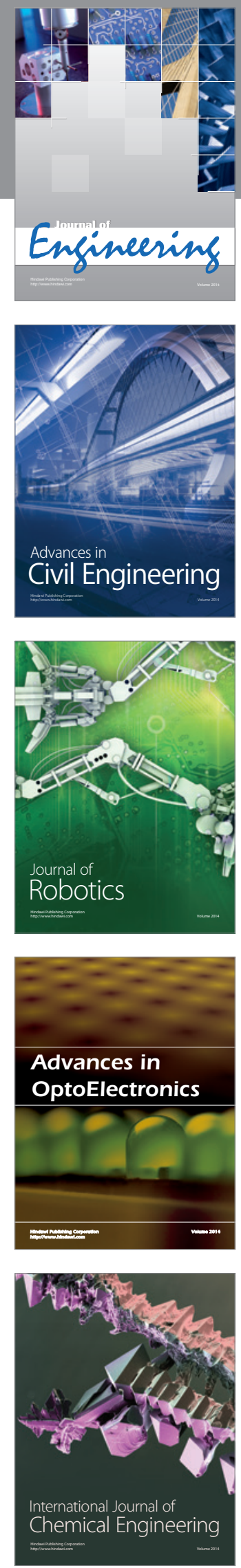

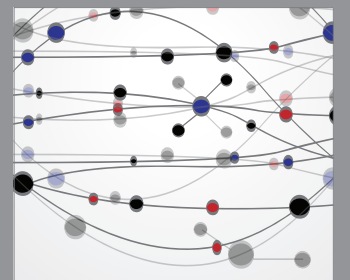

The Scientific World Journal
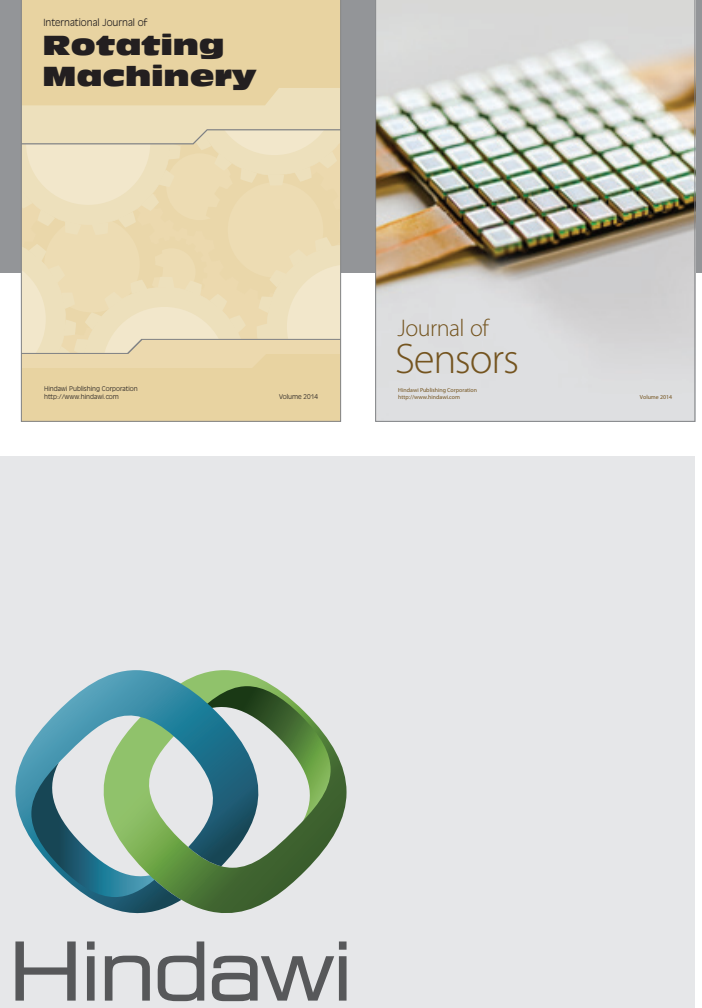

Submit your manuscripts at http://www.hindawi.com
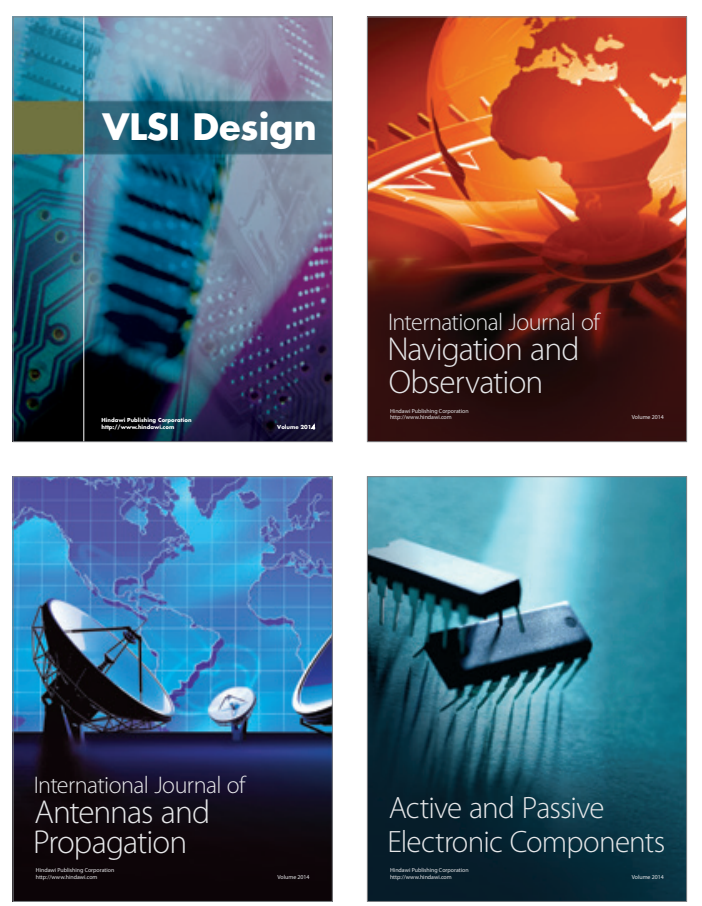
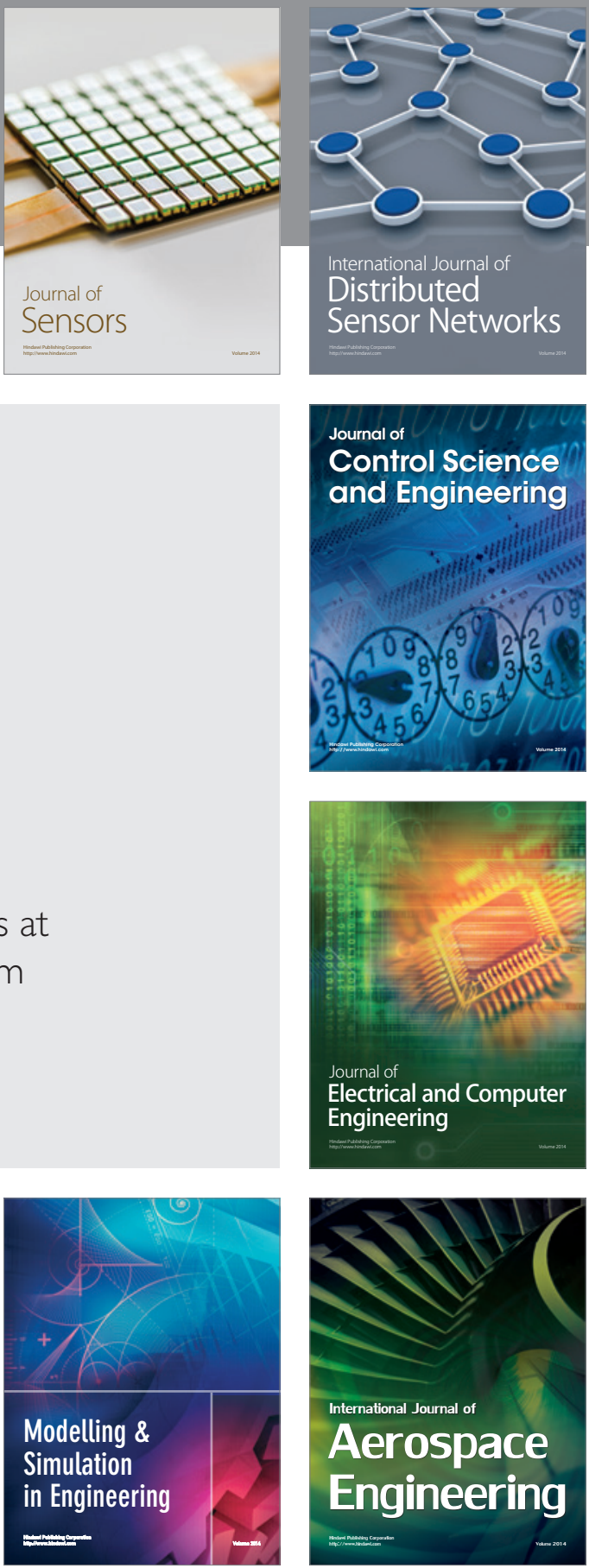

Journal of

Control Science

and Engineering
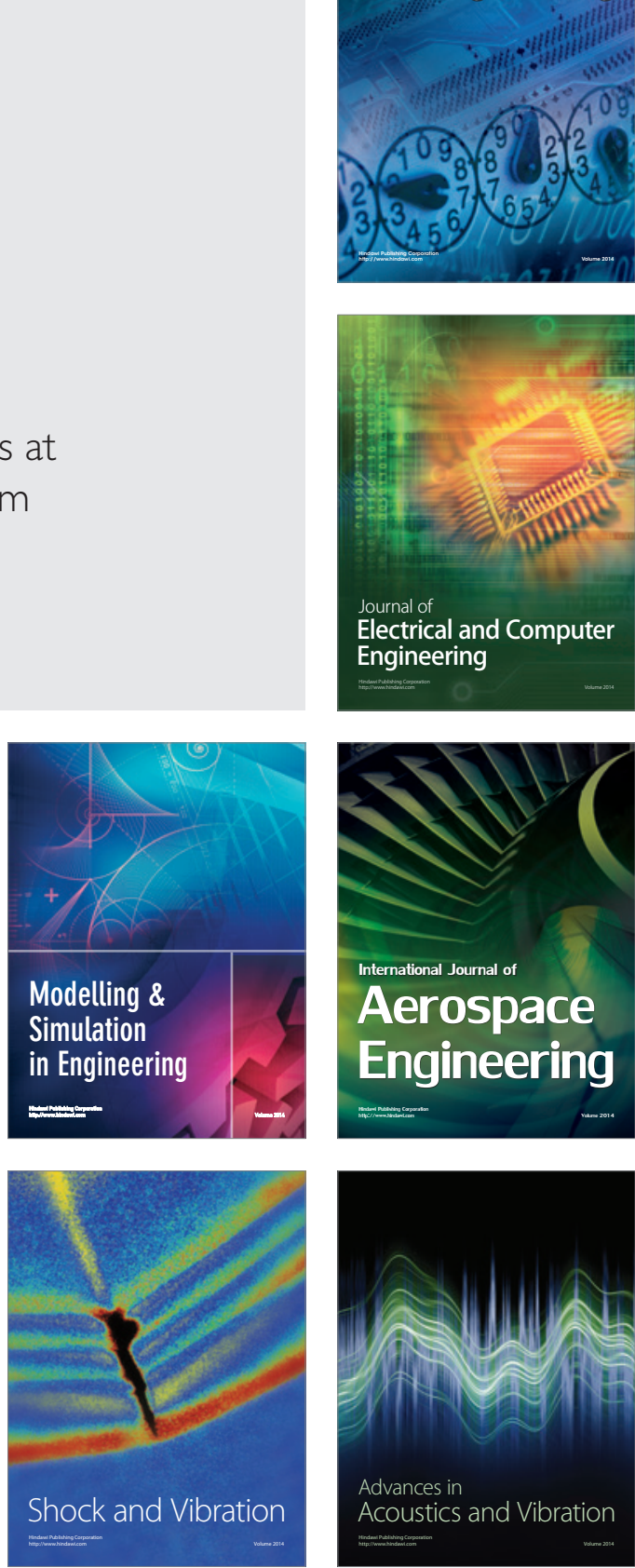